Rochester Institute of Technology

RIT Scholar Works

Presentations and other scholarship

Faculty \& Staff Scholarship

Spring 2020

\title{
An Examination of the Work Practices of Crowdfarms
}

\author{
Yihong Wang \\ University of Liverpool \\ Konstantinos Papangelis \\ Rochester Institute of Technology \\ Michael Saker \\ City, University of London \\ Ioanna Lykourentzou \\ Utrecht University \\ Vassilis-Javed Khan \\ Eindhoven University of Technology
}

See next page for additional authors

Follow this and additional works at: https://scholarworks.rit.edu/other

Part of the Other Computer Sciences Commons

\section{Recommended Citation}

Yihong Wang, Konstantinos Papangelis, Michael Saker, loanna Lykourentzou, Vassilis-Javed Khan, AlanChamberlain, Yong Yue, and Jonathan Grudin. 2021. An Examination of the Work Practices of Crowdfarms. InCHI 2021 Conference on Human Factors in Computing Systems, May 08-13, 2021, Yokohama, Japan.ACM, New York, NY, USA, 23 pages. https://doi.org/10.1145/3411764.3445603

This Conference Proceeding is brought to you for free and open access by the Faculty \& Staff Scholarship at RIT Scholar Works. It has been accepted for inclusion in Presentations and other scholarship by an authorized administrator of RIT Scholar Works. For more information, please contact ritscholarworks@rit.edu. 


\section{Authors}

Yihong Wang, Konstantinos Papangelis, Michael Saker, loanna Lykourentzou, Vassilis-Javed Khan, Alan Chamberlain, and Jonathan Grudin 


\title{
An Examination of the Work Practices of Crowdfarms
}

\author{
YIHONG WANG, Xi'an Jiaotong-Liverpool University, China \\ KONSTANTINOS PAPANGELIS, Rochester Institute of Technology, United States of America \\ MICHAEL SAKER, City University London, United Kingdom \\ IOANNA LYKOURENTZOU, Utrecht University, Netherlands \\ VASSILIS-JAVED KHAN, Sappi, Netherlands \\ ALAN CHAMBERLAIN, Univerity of Nottingham, United Kingdom \\ YONG YUE, Xi'an Jiaotong-Liverpool University, China \\ JONATHAN GRUDIN, Microsoft, United States of America
}

\begin{abstract}
Crowdsourcing is a new value creation business model. Annual revenue of the Chinese market alone is hundreds of millions of dollars, yet few studies have focused on the practices of the Chinese crowdsourcing workforce, and those that do mainly focus on solo crowdworkers. We have extended our study of solo crowdworker practices to include crowdfarms, a relatively new entry to the gig economy: small companies that carry out crowdwork as a key part of their business. We report here on interviews of people who work in 53 crowdfarms. We describe how crowdfarms procure jobs, carry out macrotasks and microtasks, manage their reputation, and employ different management practices to motivate crowdworkers and customers.
\end{abstract}

\section{CCS Concepts: • Information systems $\rightarrow$ Crowdsourcing.}

Additional Key Words and Phrases: Crowdsourcing; Crowdfarms; Work Practices

\section{ACM Reference Format:}

Yihong Wang, Konstantinos Papangelis, Michael Saker, Ioanna Lykourentzou, Vassilis-Javed Khan, Alan Chamberlain, Yong Yue, and Jonathan Grudin. 2021. An Examination of the Work Practices of Crowdfarms. In CHI 2021 Conference on Human Factors in Computing Systems, May 08-13, 2021, Yokohama, Japan. ACM, New York, NY, USA, 23 pages. https://doi.org/10.1145/3411764.3445603

\section{INTRODUCTION}

To frame our research, we align the term 'crowdsourcing' with existing literature. Crowdsourcing relates to individuals or organisations that put out an 'open-call' [24] for tasks that they want completed. Interested workers can tender for these tasks and earn money by completing them remotely. Solo crowdworkers make up most of this large, growing digital workforce. They usually undertake crowdwork part-time, work from home, and take on self-contained tasks that require few specialized skills $[4,32]$. Solo crowdworkers using human intelligence to rival the effectiveness of computational systems have been remarkably successful at data clustering, content labelling and other relatively short and simple tasks $[1,40]$. Crowdsourcing is regarded as a new value creation model in China, invigorating China's IT industries [70]. According to Huo, Zheng and Tu [55], in 2017, 30 million Chinese crowdworkers served more than 190,000 enterprises and individuals, generating a total business turnover of $\mathrm{CNY}$ five billion (approximately $\$ 700 \mathrm{M}$ ). At the time of

Permission to make digital or hard copies of all or part of this work for personal or classroom use is granted without fee provided that copies are not made or distributed for profit or commercial advantage and that copies bear this notice and the full citation on the first page. Copyrights for components of this work owned by others than the author(s) must be honored. Abstracting with credit is permitted. To copy otherwise, or republish, to post on servers or to redistribute to lists, requires prior specific permission and/or a fee. Request permissions from permissions@acm.org.

CHI'21, May 08-13, 2021, Yokohama, Japan

(C) 2021 Copyright held by the owner/author(s). Publication rights licensed to ACM.

ACM ISBN 978-1-4503-XXXX-X/18/06 ..\$15.00

https://doi.org/10.1145/3411764.3445603 
Yihong Wang, Konstantinos Papangelis, Michael Saker, loanna Lykourentzou, Vassilis-Javed Khan, Alan Chamberlain, CHI'21, May 08-13, 2021, Yokohama, Japan

Yong Yue, and Jonathan Grudin

writing, $\mathrm{ZBJ}^{1}$ and EPWK ${ }^{2}$, two of the most prominent crowdsourcing platforms in China, support around 19 million active crowdworkers and cover a wide range of tasks, ranging from click-work to product design and software development.

Some of the more complex tasks posted on crowdsourcing platforms, such as engineering and software development, require higher levels of expertise or more diverse skills than solo crowdworkers can provide [38]. In response, crowdsourcing platforms can promote crowdworkers functioning as teams. This has recently appeared in the West. For example, in 2019 Upwork unveiled a service called "Agency Experience," ${ }^{3}$ to support boutique agencies: small firms specializing in larger, complex and high-value crowdtasks. Fiverr announced a service called "Studios" ${ }^{4}$ that also supports crowdworkers who join forces to tackle tasks marked by complexity, scale and scope. However, organizational participation in and support for crowdsourcing arose earlier in China and has been evolving, as we describe in this paper. ZBJ, for example, promotes itself as an "incubator" of over 150,000 crowdsourcing companies and has provided direct support to these firms since 2016 It offers work spaces and dedicated services, such as financial and legal services, to what they refer to as "crowdsourcing factories" ${ }^{5}$ in 26 major cities in China. These "factories" are organizations that vie for tasks posted on the ZBJ platform and together create "united crowdsourcing communities."

A few years ago, some of us applied methods from human-computer interaction (HCI) and computer supported cooperative work (CSCW) to study solo crowdworkers and expanded our focus to include this phenomenon when we encountered it. Our early study [67], which was also one of the first empirical study of firms engaging in crowdwork, suggested that in contrast to self-employed Chinese solo crowdworkers undertaking part-time microtasks from home [69], these small organizations undertake complex and large macrotasks, employ salaried full-time workers, and operate in formal workplaces such as business premises. We attributed their emergence to the changing nature of tasks posted on the Chinese crowdsourcing platforms, together with favorable government policies such as the "mass entrepreneurship and mass innovation program" and support from platforms, such as the "ZBJ factories" noted above. To pointedly describe these companies, we dubbed them "crowdfarms." Our use of "crowdfarm" employs the relevant English "farming work out" (i.e., outsourcing) concept to identify this as a unique kind of firm, different from crowdsourcing platforms or firms that post crowdsourcing jobs. Chinese IT workers sometimes self-mockingly call themselves as "ma nong" ("code farmers" in English) to both describe the heavy pressures they encounter in digital work and support their identity and camaraderie with those doing similar jobs [60]. Given the mixed connotations of the term "ma nong" or "code farmer," we decided to use the respectful "crowdfarm worker," not "crowdfarmer," to avoid any appearance of insensitivity toward people whose work we value.

A subsequent study [68] found that solo crowdworkers and crowdfarm workers differ in terms of their work environments, task-related problems, career development, rewards, reputation management, and work-life balance. It also found that crowdfarms differed from traditional small and medium size businesses in that they moved from offline business to online crowdwork for the sole purpose of capitalizing on crowdsourcing opportunities. Earnings from crowd tasks had sharply increased in most crowdfarms we interviewed. Most workers believed that crowdwork would soon become their primary source of income, rather than being secondary to off-line work.

Those studies revealed an interesting, emergent form of digital labor but did not provide a detailed account of how crowdfarms carry out tasks. Experimental studies of ad hoc groups of crowdworkers

\footnotetext{
${ }^{1}$ https://www.zbj.com

${ }^{2}$ https://www.epwk.com/

${ }^{3}$ https://www.upwork.com/blog/2019/07/new-agency-experience/

${ }^{4}$ https://www.fiverr.com/stores/studios

${ }^{5}$ https://work.zbj.com/
} 
recruited for tasks have shown that decision-making, collaboration and task operation can be influenced by varying the organizational workflow $[45,64]$. This paper examines the work practices of crowdfarms to provide a deeper understanding of this new workforce in the wild. We conducted 53 interviews of workers from 53 crowdfarms affiliated with ZBJ, the largest Chinese crowdsourcing platform. The interviews focused on identifying work-related organizational and task characteristics and explored the workflows of task procurement, task execution, and reputation management.

The key contributions to the CSCW and HCI fields are:

(1) A detailed investigation that identifies work-related characteristics of a novel type of companybased crowd workforce. This could motivate further scholarly inspections of companies participating in crowdsourcing and how they spread or evolve into other forms of work organization across the gig economy more generally.

(2) An understanding that crowdwork practices in crowdfarms can have positive or negative impacts on other crowdsourcing stakeholders: solo crowdworkers, task requestors, and platform companies.

(3) High-level recommendations for crowdsourcing platforms, taking into account the needs and operational and work-related characteristics of crowdfarms. These include: (1) increasing the transparency of the bidding mechanism for macrotasks; (2) refining the task system to enable requestors to decide whether or not to permit a crowdfarm to subcontract tasks; (3) developing strategies to regulate and normalize the potential secondary market formed by task subcontracting; and (4) establishing distinct rating systems for macrotasks and microtasks.

The paper is organised as follows: After reviewing relevant literature, we outline our methodological and data analysis designs. We then present our findings, detailing how crowdfarming companies are organized for crowdwork, and common types of tasks that they undertake. We identify work practices along three axes: task procurement, task execution, and reputation management following task completion. We conclude with a discussion of the findings, a reflection on study limitations, and consideration of possible directions for future research.

\section{BACKGROUND}

\subsection{Crowdsourcing and type of crowdwork}

Since Jeff Howe coined the portmanteau "crowdsourcing" in 2006 [24], it has been employed to describe tasks in different areas [44, 65]. Several studies showed that crowdsourcing can be a powerful tool to solve problems in which human intelligence is more efficient or effective than computer systems, such as for classifying pictures [1, 40]. With Wilogo and Crowdspring as examples, Schenk and Guittard [51] showed that companies and individuals can use crowdsourcing to attract creative and novel ways to market their products and contents. By posting tasks related to specific issues such as public concerns, health symptoms and financial contribution, scholars have also shown that crowdsourcing is applicable to governmental policy-making, medical experiments, and the creation of initiatives and enterprises [6, 53, 61].

Crowdsourced tasks can be categorized as microtasks or macrotasks. Microtasks are short, simple tasks that can be completed reasonably quickly by an individual without relying on others $[12,18]$. Examples are data collection and analysis [41], labeling or classifying images or other content [26, 50], spelling and grammar checking for short paragraphs [71], and captioning audio in real-time for accessibility [33]. Macrotasks are larger and more complex. They may require or benefit from collaboration among crowdworkers and often involve a range of skills. [32, 38]. Examples of macrotasks are software development [47], product design [52] and document writing [63]. 
Yihong Wang, Konstantinos Papangelis, Michael Saker, loanna Lykourentzou, Vassilis-Javed Khan, Alan Chamberlain, CHI'21, May 08-13, 2021, Yokohama, Japan

Yong Yue, and Jonathan Grudin

\subsection{Work practice of crowdworkers}

The marked diversity of crowdsourcing and crowd tasks have prompted scholarly interest in the work characteristics of crowdworkers. Several studies have illustrated that crowdworkers mainly undertake microtasks that are decomposable, self-contained, small, and simple enough to be performed repeatedly [14, 25]. As noted above, these tasks can include surveys, content (e.g. image) labelling and transcription [27, 59]. Research into the work environment of crowdworkers found that across various platforms (e.g. Amazon Mechanical Turk, CrowdFlower) they prefer working from home, enjoying the flexibility (e.g. taking care of children while crowdworking) and work efficiency facilitated by their home environment $[5,12]$. In the context of task rewards, both financial compensation (e.g. payment for tasks) and non-financial compensation (e.g. acquired knowledge, skills and expertise) are important to crowdworkers. Ross et al [48] reported that over $90 \%$ of the crowdworkers on Amazon Mechanical Turk posit that the significance of their earning involves the ability to support their hobbies or make their basic ends meet. With respect to non-financial rewards, Jiang, Wanger and Nardi [29] suggest that crowdworkers learn about a rapidly changing world through their exposure to diverse information obtained in crowd tasks, and can experience emotional fulfillment by helping others complete their assignments. To this end the acquired skills and knowledge from crowd work in Margaryan's study [39] helped workers improve their task performance nd enhance their career potential.

Several studies have investigated how crowdworkers procure tasks. According to Law and von Ahn [35], it mainly involves two central modes: (1) pull and (2) push. In the pull mode (e.g., Amazon Mechanical Turk), crowdworkers select tasks themselves based on personal preferences, such as the payment for tasks [9], the duration and complexity of tasks [43], and the conciseness of the instruction and requirements of tasks [49]. Finding crowdworkers who are driven by personal development and tend to choose jobs that improve their expertise, Kaufmann, Schulze and Veit [31] propose that these motivations can affect which crowd tasks are selected. In contrast, crowdworkers in the push mode (e.g. Clixsense and Zooniverse $[8,28]$ ) are allocated and assigned tasks based on a series of constraints regulated by requestors. These constraints includes the level of skill required [23], performance on previous tasks [30], the maximum number of attempts for the task [28], and, in some mobile crowdsourcing scenarios, the time available, as well as the geographical location [57]. The push-oriented mode is popular for task procurement of both paid and voluntary crowdworkers.

Crowdsourcing studies have also focused on how crowdworkers process tasks. Early research on the topic found that crowdworkers often undertake tasks independently [3, 24], but Gary et al. [20] demonstrated that the crowd is also a collaborative network in which crowdworkers (1) share administrative overheads with each other to reduce costs of managing the work process, (2) exchange information about tasks and requestors to increase the opportunities of crowdwork, and (3) help others complete tasks and advance them through teaching task-related skills, which can include time management, search queries and executing basic scripts. Morries et al [42] suggest that crowdworkers could better cooperate by subcontracting work sand thereby develop new skills, such as task management and design, while other workers, especially novice and casual workers, could benefit from the lower barriers of smaller and simpler subcontracted tasks. Having identified 10 cooperative ways crowdworkers handle tasks, D'Eon et al. [13] contend that workers are now better at solving creative writing tasks, cognitive tasks marked by their difficulty, tasks with unclear or subjective guidelines, and tasks requiring further division.

A third significant crowdwork practice is reputation management. In a study examining the reputation of Indian Amazon Mechanical Turk workers, for instance, Gupta et al [21] illustrate that the work of reputation management falls on the shoulders of crowdworkers wherever the challenge to their reputation lies. To protect reputation, these crowdworkers tend to take defensive 
and preparatory tactics such as ensuring that they are capable of doing the tasks before accepting them, getting training for tasks, and specialising in certain types of tasks for familiar requestors. Similar strategies were also observed among the Eight crowdworkers [22]. Many workers would return in-progress tasks if the complexity exceeded their current ability and might, therefore, risk submitting low-quality work that could negatively impact their reputation [22].

\subsection{Crowdsourcing in China}

The literature cited above provides a thematic schema to examine crowdworkers and their work practices. Only a few researchers have addressed crowdsourcing in China. Huo and Zhao [54] conducted a study with 269 Chinese crowdworkers and found that $59 \%$ of the participants were independent crowdworkers between 20 and 25 years old. They are also in general well-educated, given that approximately $85 \%$ had bachelors degrees or above, $14 \%$ graduated from high school or vocational school; only less than $1 \%$ were junior high school graduates or lower. In our study [69], $87 \%$ of the crowdworkers on the ZBJ platform did crowdwork part-time, with income and acquired knowledge or skills the most important rewards. Feng and Huang [16] reported that Chinese crowdworkers also consider personal interests and the opportunity of self-development in choosing tasks. Yang et al. [72] reported some Chinese crowdworkers compete for tasks that have less participants, to increase the opportunity of winning bids, as well as tasks likely to yield larger rewards. In a similar vein, Shi [56] proposes that many Chinese crowdworkers seek easier, wellpaying tasks with longer task duration, while workers with higher reputations often take on challenging tasks that can reap more lucrative rewards.

These studies provide insight into crowdsourcing in China, but not to crowdfarms, where our earlier work found that work experiences differ markedly from those of solo crowdworkers in attitudes towards tasks, rewards and reputation. [67] [68] This study was undertaken to obtain insight into how these companies engage in crowdwork, focusing on crowdfarm workers and managers who contract tasks on the largest Chinese crowdsourcing platform, ZBJ. We examined their organizational characteristics, task characteristics, task procurement, how they carried out tasks, and how they managed their reputation.

\section{METHODOLOGY}

We conducted a series of semi-structured telephone interviews with Chinese crowdfarm workers and managers who work in the largest Chinese crowdsourcing platform, ZBJ. To do so, we first posted a request for interviews as a task on ZBJ. After investigating the crowdworker payment for the similar type of tasks, an above-average payment of $120 \mathrm{CNY}$ (approx. US\$17 USD) was offered per interview. Unsure of the exact population of active crowdfarms, we decided to utilize the straightforward opportunistic sampling method to obtain timely and initial primary data. However, to balance the practicality and the representativeness of our sample, we clearly stated that our study was targeted at crowdfarm workers in companies in which crowd tasks are taken as part of the formal business. We also conducted an initial online discussion asking work-related questions about the types of crowd tasks their companies usually do, their roles, and what they usually do in their role. This was to avoid potential biases such as most crowdfarms being from the same industry or most participants doing similar tasks. As ethical considerations we specified that each interview was expected to take at least 30 minutes to complete, all data collected in the study would be anonymous and confidential, and the participants were welcome to contact researchers with any concerns.

In total, 53 individuals from 53 crowdfarms were recruited. They comprised 29 crowdfarm workers and 24 crowdfarm managers. Crowdfarm worker in this context refers to an individual who solely undertook tasks, while the managers included nine who manage "projects" or run 
Yihong Wang, Konstantinos Papangelis, Michael Saker, loanna Lykourentzou, Vassilis-Javed Khan, Alan Chamberlain, CHI'21, May 08-13, 2021, Yokohama, Japan

Yong Yue, and Jonathan Grudin

the crowdfarm at a high level and 15 team leaders who partly engage in managerial work (e.g., allocating tasks to team members) while also engaging in detailed crowdwork. They were on average 30 years old $-41 / 53$ were either in their late 20 s or early to mid-30s, while a handful $(12 / 53)$ were over 40 . The majority were well-educated: 49 participants had graduated from vocational schools or higher education institutions; four had high school or pre-high school education. All earned at least $5000 \mathrm{CNY}$ (approx. US\$714 USD) every month and 28 of the 53 earned over 10000 CNY monthly (approx. US\$1449 USD). This is well above the national average monthly income in China (approximately US $\$ 340$ in 2018).

The 53 crowdfarms in our study are private companies that undertake crowdwork specialized in certain business areas: 23 specialize in IT-related tasks such as software development; 16 mainly undertake logo or industrial design tasks and the other 14 are media companies providing advertising and business planning services. Most (42/53) tend to hire experienced full-time workers based on their primary work focus (e.g., IT crowdfarms hire more developers) while the others $(11 / 53)$ also recruit novices, such as graduates. Most (44/53) chose to work in business premises with infrastructures such as a lobby, multimedia rooms and a stable Internet connection; the other nine operated from residential apartment buildings where employees can also live (See Figure 1 for a typical work environment of a crowdfarm worker). Most of the crowdfarms are small: 28/53 have fewer than 10 employees, 19 have between 10 and 20, and only six employed more than 20 workers.

All interviews were conducted in Chinese. Most lasted between 35 minutes and 50 minutes with four around 30 minutes and seven more than an hour. Consistent with previous crowdwork studies covered in the Background section, our interviews revolved around the following themes: (1) how crowdfarms organize for crowdwork; (2) the characteristics of the macrotasks and microtasks that they usually do; (3) details in task procurement; (4) the execution of procured tasks, including both internal collaboration and task subcontracting; (5) reputation management strategies, including post-task maintenance and active efforts to publicize and advertise. During the interviews, we utilized objective data (e.g., number of workers in crowdfarm) and subjective data (e.g., opinions from crowdfarm workers) as ad-hoc probes to evoke important activities and practices and to clarify ambiguous answers to obtain deeper understanding of a particular situation, such as task subcontracting.

Data analysis went through the following stages: (1) familiarization with the data, (2) the development of a thematic framework, and (3) coding of the data. During the familiarization phase, all interview data were translated from Chinese to English and transcribed by two Chinese researchers. To ensure the quality of the transcript, an external language expert was also involved to confirm the accuracy of the translation. We then started to create an initial thematic framework based on the translated transcript, focusing on (1) crowdwork practices as detailed in the related literature and (2) topics that surfaced during the familiarization phase. Then, the data were coded independently by three researchers including the two Chinese researchers and an English-speaking co-author who is specialized in crowdsourcing. During this stage, we used exact quotes from participants to inductively identify potential themes and emerging patterns within the data, before collating all the relevant coded data extracts within established themes, drawing on our preliminary framework as a suitable schema. We then examined the inter-coder agreement, first calculating the Cohen's $\kappa$ index and then the $\kappa$ coefficient across coder pairs using average $\mathrm{P}(\mathrm{e})$ values. Cohen's $\kappa(\mathrm{m})=0.766$ (95\% confidence intervals 0.100 to 0.212 )) and $\mathrm{p}<0.0005$. This result indicates a good strength of agreement and that the coding is reliable and non-random.

Once the coding phase was completed, we continued to refine our initial thematic framework by discussing the individual construct in a team meeting to resolve issues such as clarifying the broad definition with low IRR, collectively reviewing the coded data extracts, and revisiting the data-set in its entirety. This enabled us to iron-out any disagreements that arose during the analysis, to 


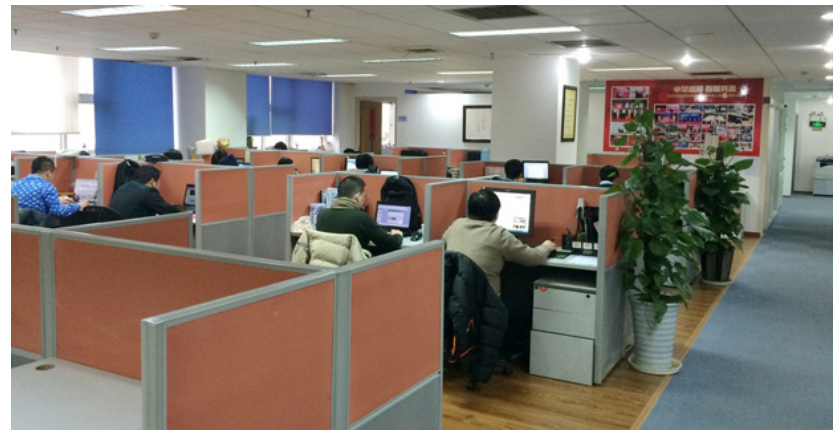

Fig. 1. An example of a typical work environment of a crowdfarm. The image was provided by one of the participants during the interviews. They have consented for the photo to be published.

ascertain whether the themes "worked" in relation to the dataset, and to identify additional themes beyond our existing schema. When we were confident that we had a coherent account based on a proper thematic framework fitting our data-set, we had completed the analysis process.

\section{FINDINGS}

\subsection{Organizational characteristics}

The overwhelming majority of the crowdfarms in our study (51/53) are well-organized, with hierarchic working structure in their crowdwork. Crowdfarm workers undertake tasks in teams divided by expertise, team leaders manage these specialized teams and also take on detailed crowdwork, and managers are in charge of the overall crowdwork process including task procurement, carrying out tasks, and reputation management. However, the crowdfarms in our study are not typically managed autocratically. Many (47/53) combined top-down and bottom-up approaches, with crowdfarm workers engaging in the decision-making process at different stages, such as crowdwork selection and decomposition. For the most part, this finding echoes previous crowdsourcing studies, which largely suggest that crowdsourcing processes blend the hierarchical management of a problem-solving domain and the bottom-up solution process of crowdworkers (e.g. [7]). P1 illustrate crowdfarm composition and practice:

"We conduct our work in a rented office on a business premise. [...] Our company has 10 full-time employees in total. Based on their skills, I divided them into 2 specialized teams a sales team that is mainly responsible for the connection with requestors and a technical team that mainly carry out the detailed tasks. Each team has one leader. As the boss, my main job is to coordinate and supervise all their works. [...] Sometimes, the employees would also participate in different decision processes, such as selecting crowd tasks that they prefer to do." (P1, 33 years old, male, design crowdfarm)

Crowdfarms organization may be inherited from past practices: we found that all 53 crowdfarms did offline business before they engaged in online crowdwork. This indicates that traditional organizational approaches can be adapted in the crowdsourcing context. However, in contrast with our earlier study [68] that found many crowdfarms relying primarily on offline work for revenue, most of the 53 in this study have moved or are moving away from the traditional business context to crowdsourcing. Specifically, for 11, crowdwork yields only about $20 \%$ to $30 \%$ of their revenue; for 25 , crowdwork earnings represent nearly half of their total revenue (e.g., $40 \%$ ); and 17 now 
Yihong Wang, Konstantinos Papangelis, Michael Saker, loanna Lykourentzou, Vassilis-Javed Khan, Alan Chamberlain, CHI'21, May 08-13, 2021, Yokohama, Japan

Yong Yue, and Jonathan Grudin

rely on crowdwork for over half of their income. The majority (45/53) indicated that the primary motivation is monetary: crowdwork enables them to diversify their income streams and reach a broader range of customers who may subsequently bring business directly to them. Many are also motivated by finding projects matched to their particular skills and expertise (33/53). In this respect, the diversity of crowdwork enables them to select tasks much as typical solo crowdworkers do, motivated by a combination of intrinsic factors (e.g., skill variety) and extrinsic factors (e.g., immediate payoff) [31]. This is reflected in the following participant comment:

"We used to rely on offline business but we are now changing our business focus to crowdwork that now accounts for around 40\% of our total income. [...] One of the reasons is that the online tasks are more diverse so that we can find the job that can best use our expertise. For example, the customers who come to our physical store usually need some simple work on fixing contaminated photos or contracts, while we took a large project from a requestor who needed hundreds of sophisticated brochures for his company's annual meeting, which really require some craftsmanship." (P2, 30 years old, male, media crowdfarm)

\subsection{Task characteristics}

All 53 of the crowdfarms chiefly do macrotasks. Typical macrotasks are full-featured website/application development, product design, and business activity planning. In contrast with microtasks, requestors who post macrotasks on the ZBJ platform seek an all-round solution to a large task rather than multiple submissions for different work units. Thus, macrotasks usually involve significant work with complex requirements, on which crowdfarm workers operate collaboratively as a team for a number of weeks. ZBJ designed a specific bidding mechanism for macrotasks. The number of bidders (i.e., crowdworkers/crowdfarms) is limited to eight to avoid excessive competition for one job. To improve the efficiency of the bidding process, interested parties can post on the task page prior to submitting any completed work and then communicate with requestors about potential solutions via phone calls, starting the work only when formally selected. Payments for macrotasks are often substantial, so ZBJ may require requestors and selected crowdfarm/crowdworkers to sign a legal contract to protect both parties. When we asked our participants why they predominantly undertake macrotasks, the reason resoundly was that they pay better than microtasks. Many $(32 / 53)$ also noted that macrotasks enable them to more fully utilize their company's expertise. P3 illustrated the importance of macrotasks to their crowdfarms:

"Our company prefers to do macrotasks. On the one hand, this type of task usually pays more. For example, it took us two weeks to complete a task worth 50,000 CNY, which was to develop a management software for an enterprise. On the other hand, this kind of large-scale task usually requires the participation of all employees of the company, so that we can make full use of everyone's strengths and everyone can earn their share." (P3, 23 years old, male, IT crowdfarm)

The crowdfarms in our study also bid for some microtasks. These include human intelligence tasks, such as data clustering as well as more creative tasks such as production of a logo/webpage/slogan. Requestors tend to seek multiple submissions for these tasks, yet offer lower payments as the work is less complex and can usually be handled by a single crowdworker or crowdfarm worker in minutes to hours. The bidding mechanism of microtasks on the ZBJ platform is similar to that on other crowdsourcing platforms, such as Amazon Mechanical Turk. Participants (crowdworkers/crowdfarms) directly submit the exact required solutions to bid with others while there are no restrictions on the number of bidders and no contract involved in the process. When we asked why 
a crowdfarm also took on microtasks, most participants (47/53) described it as vital supplementary income to fill the profit vacuum between macrotasks. Interestingly, some (18/53) also mentioned that they take small tasks to train new employees - both in understanding the crowdworking model and the context in which they operate and to cultivate task-related skills of new employees so that they can further participate in crowdfarm work. These crowdfarm practices parallel those of solo crowdworkers who take on tasks to build reputation [21] and capabilities [39] for better engagement in future tasks. P4 shared the following about microtasks:

"Our company sometimes takes small tasks like logo/icon design and assigns them to the new employees. It would be best if they won the bid and got accepted by requestors, but the main purpose of doing this is to familiarize them with the workflow and to develop their skills so that they can participate more quickly in the larger projects we have." ( $\mathrm{P} 4$, 35 years old, female, design company)

\subsection{Task procurement}

4.3.1 Macrotasks. Not surprisingly we found that crowdfarm management leads in selecting macrotasks. In 39 companies decisions were made solely by managers, in 14 by managers and team leaders. This is consistent with our previous finding crowdfarm workers usually undertake large and complex tasks assigned by managers [68]. Although seven participants said that crowdfarm workers should also be involved in the selection of macrotasks, the others felt that management should select macrotasks. Their reasoning was that management better understand the work arrangement and the expertise possessed by each team/worker and can thus better assess specialized tasks requiring collaborations, and that confining the discussion to management would accelerate the decision-making process and procure macrotasks more efficiently.

When we inquired about the factors affecting macrotask selection, both the crowdfarm workers $(29 / 53)$ and managers (24/53) in our study mentioned that their companies prefer to choose those with higher remuneration. Another factor is task feasibility: is the task in a field they specialize in and do they possess the ability to complete the task on time. Five participants mentioned that the preciseness of requirements is also important; ill-defined requirements are less likely to be selected. Precise requirements allow workers to focus energy on the task rather than deciphering the requisites and increases the likelihood that their deliverables will be accepted. This finding extends research that indicates that ambiguous task instructions negatively affect the performance of crowdworkers [19] to outcomes for large and complex crowd tasks. P5 described how he selects macrotasks for his crowdfarms:

"First of all, I will consider whether the task price is reasonable. If the payment of the task is lower than the labor cost of my employees, then I will not do it. Secondly, I will see if we have the ability to complete this task in case we fail and get bad ratings. Another factor is that the requirements of the task must be clear. If the requestors themselves do not even know what they need, then we have to spend a lot of extra energy on communicating with him instead of working on the tasks." (P5, 34 years old, male, media crowdfarm)

After a desirable macrotask is identified, a crowdfarm communicates with the requestor. All crowdfarms in our study followed the bidding mechanism designed by ZBJ platform (see section 4.2), posting a reply on the task page expressing their interest in doing said task. To strengthen their position against other competitors, the crowdfarms often highlight their reviews and utilize pictures to showcase macrotasks that they had completed for other requestors (Figure 2). To increase the likelihood of being selected, almost all crowdfarms in our study (47/53) also actively call requestors, 
Yihong Wang, Konstantinos Papangelis, Michael Saker, loanna Lykourentzou, Vassilis-Javed Khan, Alan Chamberlain, CHI'21, May 08-13, 2021, Yokohama, Japan

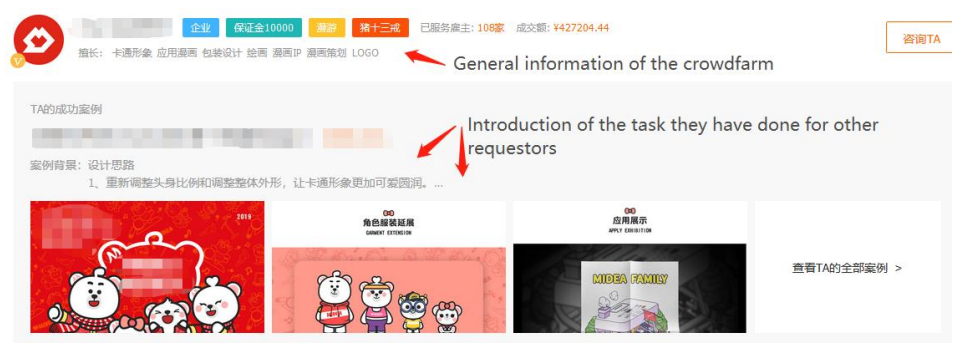

Fig. 2. An example of a typical post of a crowdfarm on a task page.

paying an additional charge (usually a few dozen CNY, a few US dollars) to get the phone number. In these communications, managers further clarify the task requirements and propose a rough solution for requestors to consider. In many cases (22/53), these discussions could extend over several days because requestors are reluctant to discuss task requirements in detail with every bidder before selecting one, and because some requestors lack task-related knowledge to accurately describe the requirements, which means crowdfarms must spend extra effort to help them figure out their needs based on their professional experience. This finding is not surprising given that strenuous communication is a major problem crowdfarm workers report with crowdwork [68].

Once crowdfarms and requestors confirm their respective intention to cooperate, and as required by the ZBJ platform, they sign a legal contract.The contract formalizes the working details of the task (objectives, duration and remuneration) and agreements regarding the management of the intellectual property (IP). This includes the acquisition of rights, such as assigning the ownership of the submitted work to requestors, and limitation of liabilities, such as crowdfarms confirming that their work does not infringe upon any third parties' intellectual property). As reported by de Beer et al., [11], contractual intellectual property management is important protection in crowdwork to protect both parties from IP-related risks. After a requestor deposits part of the total task payment (usually $20 \%-30 \%$ ) on the platform as a trusteeship, crowdfarms start to carry out the macrotask. P6, a manager from an IT crowdfarm, shared the contract signing process:

"The contract generally includes the payment of the task, deadline and the ownership of the work and so on. Sometimes requestors would ask us to apply for a domain name for the website. At this time, the contract will further involve terms like the domain names must be registered with the Chinese Ministry of Industry and Information Technology. So we have to ensure that the domain name would not infringe on the intellectual property of other companies. [...] These contracts are not only to avoid a legal dispute between us and the requestors, but also to avoid a potential dispute between us and other third-parties." (P6, female, 34 years old, IT crowdfarm)

4.3.2 Microtasks. In contrast with macrotasks, the procurement of microtasks is straightforward and similar to other crowdsourcing platforms that employ a competition mechanism. Crowdfarms select a microtask, complete it, and submit it to the requestor who evaluates all submissions and selects winners. In contrast to macrotasks, microtask selection is generally open to crowdfarm workers, with 47 companies reporting direct employee involvement, either through staff meetings $(37 / 53)$ or by allowing workers to choose autonomously from crowdsourcing platforms $(10 / 53)$, reporting to management for the record. The ability to choose tasks that chime with their interests 
has a positive effect on crowdfarm worker enthusiasm. P7 explained the value of involving workers in microtask selection:

"When choosing microtasks, our company usually consults with employees to see what kind of tasks we like. We do so via staff meetings or simply via group chat on Wechat. [...] I think doing the tasks that I am interested in is a kind of adjustment to my daily work as sometimes I will be bored by the repetitive work assigned by the management." (P7, 25 years old, male, IT crowdfarms)

Our participants also noted payment and required skills/expertise considerations, as they did with macrotasks. However, the evaluation process differed. Most (37/53) sought microtasks with better payment, tempered by consideration of task duration, as participants needed to be available for the next macrotask procured by their company. Nearly one-third of our participants (16/53) indicated that "out-of-reach" skills/expertise is not necessarily a restriction. On the contrary, participants try challenging microtasks in order to practice their skills, despite a higher risk of their work being rejected. This finding is congruent with our observation that crowdfarms utilize microtasks to train employees, and solo crowdworkers learn from failed attempts and errors [15, 39]. P8 detailed the use of microtasks to train workers:

"Our company is ok with employees doing challenging tasks. We regard it as a good way to practice their skills and expertise. However, if they fail, they have to learn from the winning bids and explain to us [the management] the reasons why his/her work is not selected and how s/he would improve in the future." (P8, 45 years old, female, design crowdfarm)

\subsection{Carrying out tasks}

4.4.1 Macrotasks. We found that some crowdfarms handle macrotasks entirely internally and others may subcontract part of the work.

\section{Working/doing tasks internally}

After procuring a macrotask, the next step is to carry it out collaboratively. A majority (29/53) start this process by formulating a work plan, with managers and team leaders decomposing the tasks into smaller work units with clear timelines before assigning them to crowdfarm workers based on their expertise. Almost half (24/53) conduct this hierarchically: managers assign the decomposed tasks to team leaders based on team expertise, after which team leaders allocate the work units to team members based on their personal skills. However, not all task decomposition and allocation is fully controlled by management. Nearly three-fifths of our participants (32/53) mentioned that the opinions of crowdfarm workers are taken into consideration as their understanding of the processes and cycles of specific work units helps management formulate a better plan. Previous crowdsourcing studies also indicated that deliberation could help crowdworkers converge on decisions, and a collaborative environment can assist in decomposing complex crowdsourcing tasks $[10,34]$. P9 described this:

"In $60 \%$ of the cases, I will formulate the work plan with team leaders who will then assign the work units they received to their team members. [...] They know better about these 
Yihong Wang, Konstantinos Papangelis, Michael Saker, loanna Lykourentzou, Vassilis-Javed Khan, Alan Chamberlain, CHI'21, May 08-13, 2021, Yokohama, Japan

staffs' expertise and detailed work arrangement than I do. [...] However, we will also seek help from our experienced employees in the task planning as they have probably done similar tasks before." (P9, 30 years old, male, media crowdfarm)

Every crowdfarm in our study proactively monitors the quality of completed work units throughout the process. This is again the responsibility of management. Most (39/53) require crowdfarm workers to report work progress via meetings or instant messages (e.g., Wechat). Team leaders and managers provide feedback based on the reports, and occasionally help workers address problems in person. Depending on task duration, reports could be made every few days or every week. The other 14 crowdfarms supervise their work through software such as Alibaba Ding Talk and Tencent TIM. According to the participants, computation-supported management enables daily supervision and manager feedback, significantly increasing the efficiency of crowdfarm work. Interestingly, four of the 14 crowdfarms developed their own management software, saving the cost of a third-party system and resulting in the customized design of functions tailored to their crowdwork practices. One company developed a sophisticated document system to manage the work units uploaded from various teams and workers. Consistent with Valentine et al. [64], we found that a computation-supported system can improve macrotask processing. Only one in four of our crowdfarms followed this approach; the others relied on general-purpose third-party software. This suggests an opportunity for crowdsourcing platforms to design cooperative work systems that support work practices of both crowdworkers and crowdfarms. P10 described how his crowdfarm uses "home-made" office software to manage work:

\begin{abstract}
"It had been very inconvenient to check the design uploaded by workers doing different tasks, so we developed software to help manage the work report. It allows us to track the progress of different tasks systematically with clear timelines and I can also provide feedback as soon as a new design is uploaded." (P10, 30 years old, male, design crowdfarms)
\end{abstract}

In addition to supervising work, management in most crowdfarms (48/53) actively communicates with requestors via social media such as Tencent QQ and Wechat to update task milestones. They could share a demonstration video that shows the prototype of the user interface or a rough picture of the product in design. For some crowdfarms (16/53), updating requestors is a way to protect their interests. The phased work units sent to the requestors are evidence that a crowdfarm has completed at least part of the task; they could be submitted to ZBJ for arbitration should a contract dispute arise. However, a more common and important reason for keeping requestors in the loop is to obtain timely feedback while further clarifying the requirements for subsequent work. Based on feedback and clarification from requestors, management conducts staff meetings to plan how to refine the completed work and, if necessary, adjust their work schedule to meet clarified requirements of subsequent work units. Improvement based on communication with requestors can continue up to the completion of all work units. The teams then work together to integrate the parts into a final deliverable under the lead of management. They then upload this on the ZBJ platform as the final submission to the requestor. Previous studies suggested that crowdworkers have limited interactions with requestors until receiving notification of their work being accepted or rejected $[12,21]$. We found that crowdfarms involved in macrotasks communicate more with requestors and thus have greater opportunity to improve their product before the final submission. P11 illustrated this: 
"Every time a function of the software is completed, I will shoot a short video and send it to the requestors via Wechat. If they are ok with it, I will double check the requirements of the following work units with them. [...] It is not very often that they are dissatisfied with our work, but if they are, I will contact the team responsible for this function or module to have a meeting and discuss how to refine it. [...] There was a company that refused to pay for the work we have done for them, so I uploaded these evidences, including the source code, to ZBF and won our money back.” (P11, 33 years old, female, IT crowdfarm)

\section{Subcontracting parts of macrotasks}

Over half of the crowdfarms (31/53) report sometimes subcontracting part of a procured macrotask to external contractors. Crowdfarms subcontract when a work unit in a procured task requires specialized techniques or expertise beyond their capability, such as a copywriting task that requires both Chinese and English versions, or when requestors are repeatedly dissatisfied with certain work units. When we asked to whom work units are subcontracted, 14 crowdfarms reported that they usually relay them to local business partners believed to possess the necessary skills. The manager of the crowdfarm explains the requirements to the partner and negotiates the price. Once a partner completes their part of the job, the crowdfarm pays them and integrates all work units before submitting to the requestor. Collaboration with other companies is a common strategy for small Chinese enterprises with insufficient labor to carry out their businesses [37]. That said, 17 of the crowdfarms, rather than relying on local business partners, usually re-crowdsource the work units back to the ZBJ platform to seek solutions from random crowdworkers or crowdfarms. Throughout the process, these crowdfarms act like a typical requestor, posting tasks with a lower payment, usually $70-80 \%$ of what they charge the requestor. We were surprised to find that the practice of re-crowdsourcing in four crowdfarms help them establish a stable group of solo crowdworkers. Although not formal employees working on core work units, these workers could be consistently involved in processing subordinate units of macrotasks; for example, designing web pages in a full-featured website development task. Again, crowdfarms usually pay these solo crowdworkers $70 \%-80 \%$ of what they charge. Although we have identified some negative effects of crowdfarm subcontracting practices [67], this indicates that while the subcontractors are paid less, some receive a flow of tasks matched to their skills and exposure to macrotask work experiences that could support career development. P12 explained why her crowdfarm subcontracts part of the procured crowdwork:

"If a requestor keeps being dissatisfied with a certain part of the copywriting we have done, then we have to subcontract this part of the work. In my opinion, this is also responsible for the overall project and the employer. [...] We usually post tasks on ZBJ or other crowdsourcing platforms and then pay for the best work.” (P12, 35 years old, female, design crowdfarm)

We asked participants how they control the quality of subcontracted work units. Echoing the process of internal collaboration, almost all of those that subcontract (29/31) receive regular work progress reports from secondary workers, which they send to requestors for feedback. Some crowdfarms (8/31) supervise more actively by assigning the employees responsible for the units to work directly with the external contractors. For the most part, this is to avoid misunderstanding by external partners or crowdworkers of the needs and intentions of requestors. Crowdfarms send someone with first-hand information to guide the process of the shifted work as a consultant. If 
Yihong Wang, Konstantinos Papangelis, Michael Saker, loanna Lykourentzou, Vassilis-Javed Khan, Alan Chamberlain, CHI'21, May 08-13, 2021, Yokohama, Japan

Yong Yue, and Jonathan Grudin

the secondary workers do not complete the shifted work as expected, crowdfarms either improve the quality of the work on their own or find a new contractor to handle it. Interestingly, in contrast with the typical crowdsourcing practice where unsatisfactory submissions are unlikely to receive any payment, a few participants (4/31) mentioned that their companies pay secondary workers at least part of the agreed remuneration as long as they complete the subcontracted task. The principal reason is that a "thank you" reward to secondary workers helps maintain a collaborative relationship. We previously described the significance to crowdfarms of actively maintaining "guanxi" - interpersonal relationships involving obligation, commitment, and exchange of favors with requestors to gain future crowdwork opportunities [68]. This finding extends the understanding of crowdfarms' work practice by revealing that some also establish collaborative relationships with secondary workers to support their crowdwork.

Finally, 31 crowdfarms exhibited mixed feelings about transparency of subcontracting practices Fourteen reported actively informing requestors or even asking for permission when subcontracting work units. They felt that requestors have the right to know how their tasks are being handled and could object to their work being shifted to an unknown third party. However, the other 17 crowdfarms conceal the subcontracting process from requestors, believing that requestors should only care about the outcome and informing them could result in a requestor questioning their professional capabilities, with a negative impact on the possibility of future business. P13 and P14 illustrated the different opinions towards the transparency of task subcontracting:

"I generally do not let requestors know that I have subcontracted their tasks, even if only a small part. This is because if the employer knows about this, it will affect his/her trust in our company's capabilities and thus affect the willingness to continue cooperating with us." (P13, 32 years old, male, design crowdfarm)

"We first negotiate with the requestors, and only subcontract the work units after getting their permissions. This is because many customers are more concerned about a satisfactory result. On the other hand, I personally think it is also a work ethic.” (P14, 28 years old, male, IT crowdfarms)

4.4.2 Microtasks. Crowdfarms take on microtasks that they are capable of handling, but three reported handing over a microtask when a new profitable macrotask came in. Twenty-six described selecting microtasks to satisfy personal interests or hobbies, rather than for financial rewards. Eleven noted that the time it would take to find an external contractor and checking their work was much more costly than doing the task on their own, which was an activity they saw as beneficial.

As with macrotasks, microtasks generally commence with planning although not decomposition. Six reported microtasks selected solely by management that were directly assigned to a crowdfarm worker who was available and had the right experience. In most cases (37/53), microtasks were procured with crowdfarm worker input and taken on voluntarily by workers. The more tasks they take on, the more bonuses they can get. In the remaining 10 crowdfarms, crowdfarm workers selected microtasks autonomously from the crowdsourcing platform and informed management about the task duration and payment for the record. After a microtask is distributed to a specific crowdfarm worker, s/he carries it out under management supervision. Due to the short task duration (usually minutes to hours), and in contrast to macrotasks, there is no in-work report. Instead, management generally examines the finished product with the crowdfarm worker when the work is completed. If it is satisfactory, s/he submits the task to bid against other participants on behalf of the company. However, if management is not satisfied with the work, they usually provide feedback and ask for modifications before submission. Although the crowdfarms we interviewed 
generally do not update the work progress to microtask requestors as they do with macrotasks, eight participants mentioned that requestors actively communicated with them when they liked their submitted work but required a further change. In such situations, nearly half of our participants $(25 / 53)$ said that management assigns another employee with more skil or expertise to help refine the finished product. This improves the overall quality and is a training opportunity for the initial worker to learn from a more experienced colleague. Previous findings that around $10 \%$ of solo crowdworkers capitalize on their social networks (e.g., friends, forums) to solve microtasks [20]; crowdfarm workers similarly gain support, provided by their employers in an organized and stable manner. After passing the re-examination by management, workers submit to requestors. P15, a manager from a design crowdfarm, shared his experience of working on microtasks:

"For smaller tasks, I generally do not require workers to report to me the progress, but still, I have to check their work before handing it over to the requestors. If a worker, such as a graduate, really cannot solve the problem independently, then I will find other old workers to play the role of a mentor to help him." (P15, 27 years old, male, design crowdfarm)

\subsection{Reputation management}

All crowdfarms in our study use diverse approaches to building and managing their reputation when conducting macrotasks or microtasks. Service speed, quality, and attitude are considered, as well as responses to comments from requestors. Although reputation management runs throughout the task process, leading to task refinement based on requestor feedback, crowdfarms focus most on it after a task is completed. Specifically, almost all crowdfarms (47/53) conduct post-task interviews with requestors-through phone calls, social media, or ZBJ's communication system)-to determine satisfaction. In 20 of the crowdfarms, this is handled by dedicated employees good at customer relations. As in earlier phases, if requestors are not completely satisfied, the crowdfarm usually spends time refining the work until it is accepted with positive ratings and comments. Although this extra work is not paid for, participants indicated that it is worthwhile. Companies typically display requestor ratings on the company profile on the crowdsourcing platform. As with travel accommodation and other product ratings, crowdfarms urge requestors to provide detailed comments on their service to make the evaluation appear authentic and credible to potential customers. Ten participants reported that when requestors were dissatisfied with the final deliverables, the company gave up part of the profit in exchange for positive ratings and comments. Although this impacted revenue, the loss of future business due to negative reviews was considered more costly.

Reputation management is not restricted to ratings and comments. Sixteen participants reported that they remained in regular contact with requestors after the completion of a job. Maintaining a working relationship could lead to additional work through requestor referrals to third parties. Eight other companies advertised on the crowdsourcing platform. Some invested to be included in the company list displayed on ZBJ's main page. Although costly, they reported that advertising gained trust from requestors when bidding against crowdfarms or crowdworkers who did not broadcast their names. Twenty-one other crowdfarms reported interest in investing in such advertisements but had not yet done so due to financial constraints. P16 described how his media company improves its reputation:

"We keep the contact information of the served requestors such as their Wechat. Sometimes we will do a few small tasks for them for free and then ask them to help promote our company in their Wechat Moment [similar to Facebook Timeline]. [...] We have also considered advertising on ZBJ after we earn more money from our crowdwork. I heard that advertisement is quite expensive." (P16, 35 years old, female, media crowdfarm) 
Yihong Wang, Konstantinos Papangelis, Michael Saker, loanna Lykourentzou, Vassilis-Javed Khan, Alan Chamberlain, CHI'21, May 08-13, 2021, Yokohama, Japan

Yong Yue, and Jonathan Grudin

\section{DISCUSSION}

Crowdfarms are companies with full-time employees, fixed workplaces and well-organized working structures. Similar to typical small and medium enterprises (SMEs) in several ways, they are distinct in representing a shifting focus from offline work to online crowdsourcing. Crowdfarms emerged in China as crowdsourced tasks grew in complexity and Chinese crowdsourcing platforms and government provided support. Our research indicates that these companies are accelerating the process to expand business channels and customer sources, find suitable tasks, and generate additional profit. Although crowdsourcing is a nascent and disruptive business model that deviates in ways from traditional business operations [66], as it scales up it increasingly interacts with the broader socio-technological environment, including government policy. Traditional business entities can dynamically engage in crowdsourcing and benefit from the new digital paradigm Crowdfarming as a new type of workforce draws on the growth of crowdsourcing to provide an alternative for companies to find crowdworkers with the right set of skills, avoiding a need to decompose a complex task into smaller tasks and find solo crowdworkers with corresponding skills. Many crowdsourcing platforms mainly support microtasking; crowdworkers in organizations with clear roles and hierarchy can perform complex and open-ended tasks better. Crowdfarms pave the way for the expansion of online macrotask completion. As a broader range of tasks are posted, crowdsourcing platforms and the workforce involved in crowdwork benefit.

Crowdfarms focus on large, complex tasks that require tight collaboration of multiple workers with different expertise. In addition to being profitable, macrotasks enable crowdfarms to fully utilize the skills of their workers. Whereas traditional consulting companies do not typically take on small crowdsourced tasks, crowdfarms do, not as a primary source of income but to fill gaps between macrotasks, to motivate employees, and as training exercises for new employees who will be taking on more complex crowdwork. A stable income stream and disciplined crowdfarm workers support the operation of sustainable crowdfarms. Although most microtasks are taken by solo crowdworkers, the participation of crowdfarms in microtasks might make this marketplace more competitive, which could make it more difficult for solo crowdworkers to compete for suitable crowdsourcing tasks that match their interests.

The process of procuring macrotasks through the $\mathrm{ZBJ}$ bidding process is significantly different from that of microtasks in terms of required pre-task communication with requestors and compulsory contract-signing required by the platform. On a positive note, this workflow enables requestors to select appropriate crowdfarms more effectively and protects the interests of both parties involved in the deal. However, instead of public bidding on the task page, as is commonly practiced with microtasks, contact between crowdfarms and requestors takes place through private phone calls, which can cause competitors to question why they lost a bid. Low transparency of process can negatively affect the concomitant trust, satisfaction, and motivation of crowdworkers $[13,17]$. As a corollary, greater transparency and clarity in notifying those who do not get the tasks would be good for both platform and crowdworkers/crowdfarms, with detailed measures considered together with the business rules (e.g., the protection of the business secrets). Because the selection of microtasks in crowdfarms is often open to crowdfarm workers and not controlled by management, it improves the work enthusiasm of the employees. This is signifcant because role-based organizational structures in crowdsourcing can bring challenges related to incentivizing workers [38]. Our finding indicates that traditional management approaches-in our case the autonomy of task selection-should be considered in the effort to organize solo crowdworkers to function as a team. Autonomy in selection and access to colleagues when necessary can lead crowdfarm workers to select challenging tasks instead of the competent ones they are assigned when working on macrotasks. Crowdfarms tend to select macrotasks in a safer manner than microtasks because (1) a failed microtask that leads 
to the loss of payment can be compensated for by the skill/expertise acquired by a worker; (2) a failed macrotask results in more severe financial loss and reputation damage affecting the future profitability of the company.

Crowdfarms carry out macrotasks and microtasks by internal collaboration of management and employees. This process includes (1) task planning pertaining to both the management and crowdfarm workers; (2) task execution based on the supervision by managers; (3) task refinement based on the feedback of managers and requestors; (4) task integration and inspection based on cooperation between teams and colleagues; and (5) the final task submission. Microtasks eliminate the need for some procedures, such as task decomposition and in-work report to managers. This confirms experimental studies that found significant differences in workflows between microtasks and larger and more complex tasks such as the formulation of work plans [46, 64]. Moreover, collaboration on microtasks is limited to a manager, the worker, and, if necessary, help from experienced colleagues. This suggests the possibility of a crowdfarm functioning as a set of ad hoc teams handling smaller tasks. Although different from the Flash Teams in which the experts are hired online [45], such specialized teams have been shown to be able to better solve microtasks requiring very high-level performance. Another distinction between the collaboration of crowdfarms and collaboration among solo crowdworkers is that the latter generally cooperate with others remotely [36], the teamwork in crowdfarms is usually face-to-face in their shared workplaces, which according to Battiston, Vidal and Kirchmaier [4] should improve the productivity of the workers, especially for urgent or complex tasks.

Over half of the crowdfarms we interviewed subcontracted macrotasks when they were unable to undertake certain work units or produce satisfactory results for requestors. In contrast, it is rarely considered cost-effective to subcontract a microtask. It is not cost-effective or desirable to shift interesting small work given that a crowdfarm will have the skills to complete it. Subcontract behavior among crowdworkers is affected by their personal skillset, interests and the payment of the tasks [42]. With macrotasks, we found that crowdfarms subcontract work to either local business partners or on crowdsourcing platforms, and over time can develop a hybrid partner-crowdsource approach: stable working groups composed of familiar crowdworkers. The collaboration between crowdfarms and local companies is understandable given that crowdfarms often began as offline businesses. Their practice of subcontracting to crowdworkers may affect the overall crowdsourcing landscape, benefiting solo crowdworkers with more opportunities from macrotasks in which they rarely participate, and enabling more connections among crowdfarms and solo crowdworkers in related industries to form a cluster effect, benefiting everyone in the business field [2]. On the other hand, subcontracting tasks has the potential of creating a secondary crowdsourcing market in which crowdfarms partially control the price of tasks and subcontracted workers work directly for subcontractors instead of requestors.

Subcontracting can raise issues of fair payment to secondary workers, the quality of subcontracted tasks, the transparency of the subcontracting process, and work ethic, noted by Morris et al [42]. Many crowdfarms in our study have taken these issues into considerations by compensating contractors reasonably well, providing a "thank you for trying" reward to submissions that are unsatisfactory, and sometimes actively supervising the quality of the shifted tasks. However, transparency and ethical challenges remain. Some crowdfarms do not inform requestors about subcontracting. Some risk deskilling and dehumanizing solo subcontractors by decomposing tasks inappropriately to an extreme level [42]. Consequently,we contend that crowdsourcing platforms should develop appropriate strategies to regulate and normalize the secondary market formed by task subcontracting by crowdfarms. For example. we found that some requestors care about their task being processed by an unknown third party and others may not, so crowdsourcing platforms could refine their task system by allowing a requestor to decide whether or not to permit 
Yihong Wang, Konstantinos Papangelis, Michael Saker, loanna Lykourentzou, Vassilis-Javed Khan, Alan Chamberlain, CHI'21, May 08-13, 2021, Yokohama, Japan

Yong Yue, and Jonathan Grudin

task subcontracting and by establishing a monitoring system to detect and report subcontracting behaviors that violate a requestors' norms.

Finally, our study shows that crowdfarms manage their image by reputation maintenance and reputation expansion. They actively attempt to produce satisfactory work for requestors with posttask and compensatory strategies: (1) post-task communication with requestors for positive ratings and comments; (2) extra work on final deliverables; and (3) discounting the final price in exchange for positive feedback. To expand their reputation, we found that about half of the crowdfarms rely on external resources, such as the requestor referrals and advertisements. These measures exceed the strategies of typical solo crowdworkers who mostly rely on preventative tactics such as sticking to familiar tasks and returning a task as soon as it is found to be difficult [21,58]. Crowdfarms also address requestor feedback during their longer macrotask engagements, enabling them to safeguard their reputations in a remedial and more effective manner with less likelihood of a desk rejection the way solo crowdworkers do, and of course in comparison to typical crowdworkers working alone with limited incomes [5], crowdfarms have more resources to deploy to manage their reputations, through advertising and employees dedicated to chasing after positive comments. However, to the best of our knowledge, no crowdsourcing platforms have taken into account the advantages crowdfarms have over solo crowdworkers in the design of their reputation system. Given the importance of reputation in the selection of requestors on workers [62], we believe that crowdsourcing platforms should (1) establish distinct rating systems for macro and microtasks to avoid differences in reputation caused by the different types of tasks performed, and (2) provide support for solo crowdworkers to "broadcast" their names and advertise their work.

Our research indicates that crowdfarms are affecting solo crowdworkers as well as crowdsource requestors and platforms. For solo crowdworkers, crowdfarms are a double-edged sword. On the one hand, profit-oriented crowdfarms rely on their advantages in teamwork and professionalism to take on as many microtasks and macrotasks as possible, which leaves solo crowdworkers at a disadvantage with the competition from specialized companies on an increasing array of tasks that have been their primary source of income. On the other hand, by decomposing a procured macrotask into smaller work units and subcontracting some of them, crowdfarms provide solo crowdworkers whose primary focus is microtasks with opportunities to take part in more advanced macrotasks, with the different skills and experiences obtained in this process helping develop their careers. For requestors, crowdfarms provide an efficient and professional one-stop crowdsourcing platform to find the expertise they require for a particular job. Requestors do not have to communicate with multiple solo crowdworkers on different sub-tasks, they can simply select one crowdfarm that decomposes and assigns tasks and later integrates the constituent parts for the requestor to consider as a whole. A risk for requestors is that the subcontracting behavior of crowdfarm may lead to unknown third parties performing aspects of tasks, increasing uncertainty about the quality of the final submission. For platforms, crowdfarms provide the opportunity to expand macrotask crowdsourcing and unleash the potential of their platforms to solve more complex problems that are economic or social in nature. From an economic point of view, expanding platform functions will attract more enterprises and individuals to post a wider variety of tasks, thereby increasing their revenue as the intermediary between crowd workforce and requestors. Nonetheless, the emergence of crowdfarms challenges the operation and management of platforms through the potential of a secondary market where subcontracting crowdfarms take charge. As a result, although crowdfarms are a small fraction of crowdwork today and it is too early to understand how this new workforce will evolve, it is our contention that further research should be undertaken by both the scholarly field and stakeholders involved in the crowdsourcing industry. 


\section{CONCLUSION}

Our study is the most detailed examination of crowdfarms to date. Although a relatively new organizational player in Chinese crowdsourcing, there are already hundreds of thousands of crowdfarms. They take on both macro and microtasks with methodical work practices and organized procedures. A comprehensive view of crowdsourcing should include crowdfarm workforces that approach tasks differently than the solo crowdworkers that have been the focus of most research. Our study also indicates that platforms that want to support crowdfarm practices and their concomitant impact on crowdsourcing should (1) increase the transparency of the bidding mechanism for crowdfarms, (2) refine their task system by adding a function allowing a requestor to decide whether to permit task subcontracting, (3) develop strategies to regulate and normalize the potential secondary market formed by the task subcontracting of crowdfarms, and (4) establish distinct rating systems for macro and microtasks, respectively.

A limitation of this study is the representativeness of the sample. The workers and managers we interviewed worked for crowdfarms that primarily conduct their business on the largest crowdsourcing platform, ZBJ. Crowdfarms on other Chinese platforms, such as .EPWK, could have different characteristics and work practices that warrant inspection. In addition, we relied on telephone interviews and the oral self-report of participants. With this firmly in mind, future research on the topic could involve (1) crowdworkers from other crowdsourcing platforms, and (2) additional methodological approaches, such as a large survey or in-crowdfarm observation of workflows with audio-video recording and note-taking. This could generate a more comprehensive understanding of how crowdfarms operate in the crowdsourcing context, adding nuance to the chief findings of this article.

With these caveats, we find that the study confirmed and extended prior research and presents a coherent, logical picture of a rapidly evolving new organizational form. Will today's relatively small crowdfarms grow and focus entirely on online work? Will they adopt more practices of traditional organizations? Will they be affected by the shift to more remote business interaction that some anticipate as a result of COVID-19?

\section{REFERENCES}

[1] You're hired! an examination of crowdsourcing incentive models in human resource tasks. page 4, 2011.

[2] Innovation sources of economies in eastern asia, 2012. OCLC: 832596065.

[3] Ittai Abraham, Omar Alonso, Vasilis Kandylas, Rajesh Patel, Aleksandrs Slivkins, Hai Wu, and Steven Shelford. Crowdsourcing gold-HIT creation at scale: Challenges and adaptive exploration approaches. page 4, 2013.

[4] Janine Berg. Income security in the on-demand economy : findings and policy lessons from a survey of crowdworkers. Technical Report 994906483402676, International Labour Organization, 2016. URL https://ideas.repec.org/p/ilo/ilowps/ 994906483402676.html.

[5] Janine Berg and International Labour Organization. Digital labour platforms and the future of work: towards decent work in the online world. 2018. ISBN 978-92-2-031024-3. OCLC: 1109457410.

[6] Daren C Brabham. Using crowdsourcing in government. page 42.

[7] Daren C. Brabham, Kurt M. Ribisl, Thomas R. Kirchner, and Jay M. Bernhardt. Crowdsourcing applications for public health. 46(2):179-187, 2014-02. ISSN 07493797. doi: 10.1016/j.amepre.2013.10.016. URL https://linkinghub.elsevier.com/ retrieve/pii/S0749379713005898.

[8] Jonathan Bragg and Andrey Kolobov. Parallel task routing for crowdsourcing. page 11, 2014.

[9] Alice M. Brawley and Cynthia L.S. Pury. Work experiences on MTurk: Job satisfaction, turnover, and information sharing. 54:531-546, 2016-01. ISSN 07475632. doi: 10.1016/j.chb.2015.08.031. URL https://linkinghub.elsevier.com/ retrieve/pii/S0747563215301072.

[10] Quanze Chen, Jonathan Bragg, Lydia B. Chilton, and Daniel S. Weld. Cicero: Multi-turn, contextual argumentation for accurate crowdsourcing. 2018-10-25. URL http://arxiv.org/abs/1810.10733.

[11] Jeremy de Beer, Ian P. McCarthy, Adam Soliman, and Emily Treen. Click here to agree: Managing intellectual property when crowdsourcing solutions. 60(2):207-217, 2017-03. ISSN 00076813. doi: 10.1016/j.bushor.2016.11.002. URL https://inkinghub.elsevier.com/retrieve/pii/S0007681316301240. 
Yihong Wang, Konstantinos Papangelis, Michael Saker, Ioanna Lykourentzou, Vassilis-Javed Khan, Alan Chamberlain, CHI'21, May 08-13, 2021, Yokohama, Japan Yong Yue, and Jonathan Grudin

[12] Xuefei Deng and K.D. Joshi. Is crowdsourcing a source of worker empowerment or exploitation? understanding crowd workers' perceptions of crowdsourcing career. International Conference on Information Systems (ICIS 2013): Reshaping Society Through Information Systems Design, 3:2350-2359, 012013.

[13] Greg d'Eon, Joslin Goh, Kate Larson, and Edith Law. Paying crowd workers for collaborative work. 3:1-24, 2019-11-07. ISSN 25730142. doi: 10.1145/3359227. URL http://dl.acm.org/citation.cfm?doid=3371885.3359227.

[14] Djellel Eddine Difallah, Michele Catasta, Gianluca Demartini, Panagiotis G. Ipeirotis, and Philippe Cudré-Mauroux. The dynamics of micro-task crowdsourcing: The case of amazon MTurk. In Proceedings of the 24th International Conference on World Wide Web-WWW'15, pages 238-247. ACM Press, 2015. ISBN 978-1-4503-3469-3. doi: 10.1145/2736277.2741685. URL http://dl.acm.org/citation.cfm?doid=2736277.2741685.

[15] Shayan Doroudi, Ece Kamar, Emma Brunskill, and Eric Horvitz. Toward a learning science for complex crowdsourcing tasks. In Proceedings of the 2016 CHI Conference on Human Factors in Computing Systems, pages 2623-2634. ACM, 201605-07. ISBN 978-1-4503-3362-7. doi: 10.1145/2858036.2858268. URL https://dl.acm.org/doi/10.1145/2858036.2858268.

[16] Xiaoliang Feng and Minxue Huang. Research on the solvers' participating motivation of crowdsourcing. (4):25-35, 2013. ISSN 1000-2154. doi: 10.14134/j.cnki.cn33-1336/f.2013.04.009.

[17] Christian Fieseler, Eliane Bucher, and Christian Pieter Hoffmann. Unfairness by design? the perceived fairness of digital labor on crowdworking platforms. 156(4):987-1005, 2019-06. ISSN 0167-4544, 1573-0697. doi: 10.1007/s10551-017-3607-2. URL http://link.springer.com/10.1007/s10551-017-3607-2.

[18] Ujwal Gadiraju, Besnik Fetahu, and Ricardo Kawase. Training workers for improving performance in crowdsourcing microtasks. In Gráinne Conole, Tomaž Klobučar, Christoph Rensing, Johannes Konert, and Elise Lavoué, editors, Design for Teaching and Learning in a Networked World, volume 9307, pages 100-114. Springer International Publishing, 2015 ISBN 978-3-319-24257-6 978-3-319-24258-3. doi: 10.1007/978-3-319-24258-3_8. URL http://link.springer.com/10.1007/ 978-3-319-24258-3_8. Series Title: Lecture Notes in Computer Science.

[19] Ujwal Gadiraju, Jie Yang, and Alessandro Bozzon. Clarity is a worthwhile quality: On the role of task clarity in microtask crowdsourcing. In Proceedings of the 28th ACM Conference on Hypertext and Social Media - HT' 17, pages 5-14. ACM Press, 2017. ISBN 978-1-4503-4708-2. doi: 10.1145/3078714.3078715. URL http://dl.acm.org/citation.cfm?doid=3078714.3078715

[20] Mary L Gray, Siddharth Suri, Syed Shoaib Ali, and Deepti Kulkarni. The Crowd is a Collaborative Network. In Proceedings of the 19th ACM Conference on Computer-Supported Cooperative Work \& Social Computing - CSCW'16, pages 134-147, San Francisco, California, USA, 2016. ACM Press. ISBN 978-1-4503-3592-8. doi: 10.1145/2818048.2819942. URL http://dl.acm.org/citation.cfm?doid=2818048.2819942.

[21] Neha Gupta, David Martin, Benjamin V. Hanrahan, and Jacki O’Neill. Turk-life in india. In Proceedings of the 18th International Conference on Supporting Group Work - GROUP '14, pages 1-11. ACM Press, 2014. ISBN 978-1-4503-3043-5. doi: 10.1145/2660398.2660403. URL http://dl.acm.org/citation.cfm?doid=2660398.2660403.

[22] Lei Han, Kevin Roitero, Ujwal Gadiraju, Cristina Sarasua, Alessandro Checco, Eddy Maddalena, and Gianluca Demartini. All those wasted hours: On task abandonment in crowdsourcing. In Proceedings of the Twelfth ACM International Conference on Web Search and Data Mining - WSDM '19, pages 321-329. ACM Press, 2019. ISBN 978-1-4503-5940-5. doi: 10.1145/3289600.3291035. URL http://dl.acm.org/citation.cfm?doid=3289600.3291035.

[23] Chien-Ju Ho and Jennifer Wortman Vaughan. Online task assignment in crowdsourcing markets. page 7.

[24] Jeff Howe. The Rise of Crowdsourcing. Wired, June 2006. ISSN 1059-1028. URL https://www.wired.com/2006/06/crowds/.

[25] Tobias Hoßfeld, Matthias Hirth, and Phuoc Tran-Gia. Modeling of crowdsourcing platforms and granularity of work organization in future internet. page 8, 2011.

[26] H Irshad, L Montaser-Kouhsari, G Waltz, O Bucur, J A Nowak, F Dong, N W Knoblauch, and A H Beck. CROWDSOURCING IMAGE ANNOTATION FOR NUCLEUS DETECTION AND SEGMENTATION IN COMPUTATIONAL PATHOLOGY: EVALUATING EXPERTS, AUTOMATED METHODS, AND THE CROWD. 2015. doi: 10.13140/2.1.4067.0721. URL http://rgdoi.net/10.13140/2.1.4067.0721.

[27] Jason T. Jacques and Per Ola Kristensson. Crowdsourcing a hit : Measuring workers ' pre-interactions on microtask markets. 2013.

[28] Ayush Jain, Akash Das Sarma, Aditya Parameswaran, and Jennifer Widom. Understanding workers, developing effective tasks, and enhancing marketplace dynamics: a study of a large crowdsourcing marketplace. 10(7):829-840, 2017-03-01. ISSN 21508097. doi: 10.14778/3067421.3067431. URL http://dl.acm.org/citation.cfm?doid=3067421.3067431.

[29] Ling Jiang, Christian Wagner, and Bonnie Nardi. Not just in it for the money: A qualitative investigation of workers' perceived benefits of micro-task crowdsourcing. In 2015 48th Hawaii International Conference on System Sciences, pages 773-782. IEEE, 2015-01. ISBN 978-1-4799-7367-5. doi: 10.1109/HICSS.2015.98. URL http://ieeexplore.ieee.org/ document/7069747/.

[30] Hyun Joon Jung. Quality assurance in crowdsourcing via matrix factorization based task routing. In Proceedings of the 23rd International Conference on World Wide Web - WWW'14 Companion, pages 3-8. ACM Press, 2014. ISBN 978-1-4503-2745-9. doi: 10.1145/2567948.2567951. URL http://dl.acm.org/citation.cfm?doid=2567948.2567951. 
[31] Nicolas Kaufmann, Thimo Schulze, and Daniel Veit. More than fun and money. worker motivation in crowdsourcing a study on mechanical turk. page 12, 2011.

[32] Aniket Kittur, Boris Smus, Susheel Khamkar, and Robert E. Kraut. CrowdForge: crowdsourcing complex work. In Proceedings of the 24th annual ACM symposium on User interface software and technology - UIST '11, page 43. ACM Press, 2011. ISBN 978-1-4503-0716-1. doi: 10.1145/2047196.2047202. URL http://dl.acm.org/citation.cfm?doid=2047196.2047202

[33] Walter Lasecki, Christopher Miller, Adam Sadilek, Andrew Abumoussa, Donato Borrello, Raja Kushalnagar, and Jeffrey Bigham. Real-time captioning by groups of non-experts. In Proceedings of the 25th annual ACM symposium on User interface software and technology - UIST '12, page 23. ACM Press, 2012. ISBN 978-1-4503-1580-7. doi: 10.1145/2380116. 2380122. URL http://dl.acm.org/citation.cfm?doid=2380116.2380122.

[34] Walter S. Lasecki, Juho Kim, Nick Rafter, Onkur Sen, Jeffrey P. Bigham, and Michael S. Bernstein. Apparition: Crowdsourced user interfaces that come to life as you sketch them. In Proceedings of the 33rd Annual ACM Conference on Human Factors in Computing Systems - CHI '15, pages 1925-1934. ACM Press, 2015. ISBN 978-1-4503-3145-6. doi: 10.1145/2702123.2702565. URL http://dl.acm.org/citation.cfm?doid=2702123.2702565.

[35] Edith Law and Luis Von Ahn. Book announcement: Human Computation. 10(3):3-4, 2011-12-01. ISSN 15519031. doi: 10.1145/2325702.2325703. URL http://dl.acm.org/citation.cfm?doid=2325702.2325703.

[36] Sang Won Lee, Rebecca Krosnick, Sun Young Park, Brandon Keelean, Sach Vaidya, Stephanie D. O'Keefe, and Walter S Lasecki. Exploring real-time collaboration in crowd-powered systems through a UI design tool. 2:1-23, 2018-11-01. ISSN 25730142. doi: 10.1145/3274373. URL http://dl.acm.org/citation.cfm?doid=3290265.3274373.

[37] Xiangfeng Liu. SME development in china: A policy perspective on SME industrial clustering. 5:37-68, 200803. URL http://www.eria.org/SME\%20Development\%20in\%20China_A\%20Policy\%20Perspective\%20on\%20SME\% 20Industrial\%20Clustering.pdf.

[38] Ioanna Lykourentzou, Vassillis-Javed Khan, Konstantinos Papangelis, and Panos Markopoulos. Macrotask crowdsourcing: An integrated definition. In Vassillis-Javed Khan, Konstantinos Papangelis, Ioanna Lykourentzou, and Panos Markopoulos, editors, Macrotask Crowdsourcing: Engaging the Crowds to Address Complex Problems, pages 1-13. Springer International Publishing, 2019. ISBN 978-3-030-12334-5. doi: 10.1007/978-3-030-12334-5_1. URL https://doi.org/10.1007/978-3-030-12334-5_1.

[39] Anoush Margaryan. Understanding crowdworkers' learning practices. Oxford, 2016. URL http://ipp.oii.ox.ac.uk/sites/ ipp/files/documents/FullPaper-CrowdworkerLearning-MargaryanForIPP-100816\%281\%29.pdf.

[40] Bart Mellebeek, Francesc Benavent, Jens Grivolla, Joan Codina, Marta R Costa-Jussa, and Rafael Banchs. Opinion mining of spanish customer comments with non-expert annotations on mechanical turk. page 8, 2010.

[41] Hitesh Mohapatra. DATA COLLECTION AND SAMPLING. 2018. doi: 10.13140/RG.2.2.16052.55688. URL http: //rgdoi.net/10.13140/RG.2.2.16052.55688. Publisher: Unpublished.

[42] Meredith Ringel Morris, Jeffrey P. Bigham, Robin Brewer, Jonathan Bragg, Anand Kulkarni, Jessie Li, and Saiph Savage. Subcontracting microwork. In Proceedings of the 2017 CHI Conference on Human Factors in Computing Systems - CHI '17, pages 1867-1876. ACM Press, 2017. ISBN 978-1-4503-4655-9. doi: 10.1145/3025453.3025687. URL http://dl.acm.org/citation.cfm?doid=3025453.3025687.

[43] Sebastian Möller. PSTR-CROWDS - subjective evaluation of media quality using a crowdsourcing approach, 2018. URL https://www.itu.int/dms_pub/itu-t/opb/tut/T-TUT-QOS-2018-PDF-E.pdf.

[44] Robbie T. Nakatsu, Elissa B. Grossman, and Charalambos L. Iacovou. A taxonomy of crowdsourcing based on task complexity. 40(6):823-834, 2014-12. ISSN 0165-5515, 1741-6485. doi: 10.1177/0165551514550140. URL http: //journals.sagepub.com/doi/10.1177/0165551514550140.

[45] Daniela Retelny, Sébastien Robaszkiewicz, Alexandra To, Walter S. Lasecki, Jay Patel, Negar Rahmati, Tulsee Doshi, Melissa Valentine, and Michael S. Bernstein. Expert crowdsourcing with flash teams. In Proceedings of the 27th Annual ACM Symposium on User Interface Software and Technology, UIST '14, pages 75-85. ACM, 2014. ISBN 978-1-4503-3069-5 doi: 10.1145/2642918.2647409. URL http://doi.acm.org/10.1145/2642918.2647409. event-place: Honolulu, Hawaii, USA

[46] Daniela Retelny, Michael S. Bernstein, and Melissa A. Valentine. No workflow can ever be enough: How crowdsourcing workflows constrain complex work. Proc. ACM Hum.-Comput. Interact., 1(CSCW), December 2017. doi: 10.1145/3134724. URL https://doi.org/10.1145/3134724.

[47] Lionel P. Robert. Crowdsourcing controls: A review and research agenda for crowdsourcing controls used for macrotasks. In Vassillis-Javed Khan, Konstantinos Papangelis, Ioanna Lykourentzou, and Panos Markopoulos, editors, Macrotask Crowdsourcing, pages 45-126. Springer International Publishing, 2019. ISBN 978-3-030-12333-8 978-3-03012334-5. doi: 10.1007/978-3-030-12334-5_3. URL http://link.springer.com/10.1007/978-3-030-12334-5_3. Series Title: Human-Computer Interaction Series.

[48] Joel Ross, Lilly Irani, M. Six Silberman, Andrew Zaldivar, and Bill Tomlinson. Who are the crowdworkers?: shifting demographics in mechanical turk. In Proceedings of the 28th of the international conference extended abstracts on Human factors in computing systems - CHI EA '10, page 2863. ACM Press, 2010. ISBN 978-1-60558-930-5. doi: 10.1145/1753846.1753873. URL http://portal.acm.org/citation.cfm?doid=1753846.1753873. 
Yihong Wang, Konstantinos Papangelis, Michael Saker, Ioanna Lykourentzou, Vassilis-Javed Khan, Alan Chamberlain, CHI'21, May 08-13, 2021, Yokohama, Japan Yong Yue, and Jonathan Grudin

[49] Spencer Rothwell, Steele Carter, Ahmad Elshenawy, and Daniela Braga. Job complexity and user attention in crowdsourcing microtasks. page 6, 2016.

[50] Cristina Sarasua, Elena Simperl, and Natalya F. Noy. CrowdMap: Crowdsourcing ontology alignment with microtasks. In Philippe Cudré-Mauroux, Jeff Heflin, Evren Sirin, Tania Tudorache, Jérôme Euzenat, Manfred Hauswirth, Josiane Xavier Parreira, Jim Hendler, Guus Schreiber, Abraham Bernstein, and Eva Blomqvist, editors, The Semantic Web - ISWC 2012, volume 7649, pages 525-541. Springer Berlin Heidelberg, 2012. ISBN 978-3-642-35175-4 978-3-642-35176-1. doi: 10.1007/978-3-642-35176-1_33. URL http://link.springer.com/10.1007/978-3-642-35176-1_33. Series Title: Lecture Notes in Computer Science.

[51] Eric Schenk. Crowdsourcing: What can be outsourced to the crowd, and why? page 29, 2009.

[52] Heinz Schmitz and Ioanna Lykourentzou. It's about time: Online macrotask sequencing in expert crowdsourcing. 2016-01-15. URL http://arxiv.org/abs/1601.04038.

[53] Armin Schwienbacher and Benjamin Larralde. Crowdfunding of small entrepreneurial ventures. 2010. ISSN $1556-5068$. doi: 10.2139/ssrn.1699183. URL http://www.ssrn.com/abstract=1699183.

[54] Huo Shengping and Zhao Wei. The effect mechanism of witkey's creative self - efficacy on their innovation behavior on the network innovation platform. 35(2):34-46, 2019. ISSN 2095-1361. doi: 10.1207/s15327906mbr0102_10.

[55] Shengping Huo, Zheng Chijian, and Hailang Tu. On the Research of Intelligent Coupling and Coordination between Employers and Witkey on the Crowd Innovation Network Platform. Journal of Xiangtan University, 41(1):94-101, January 2017. doi: 0.13715/j.cnki.jxupss.2017.01.017. URL http://www.cnki.com.cn/Article/CJFDTotal-XTDX201701017. htm.

[56] Lei Shi. Factors affecting solvers to participate in crowdsourcing: An empirical study from china, 2012-04.

[57] Houtan Shirani-Mehr, Farnoush Banaei-Kashani, and Cyrus Shahabi. Efficient viewpoint assignment for urban texture documentation. In Proceedings of the 17th ACM SIGSPATIAL International Conference on Advances in Geographic Information Systems - GIS '09, page 62. ACM Press, 2009. ISBN 978-1-60558-649-6. doi: 10.1145/1653771.1653783. URL http://portal.acm.org/citation.cfm?doid=1653771.1653783.

[58] M. Six Silberman, Lilly Irani, and Joel Ross. Ethics and tactics of professional crowdwork. 17(2):39, 2010-12-01. ISSN 15284972. doi: 10.1145/1869086.1869100. URL http://dl.acm.org/citation.cfm?doid=1869086.1869100.

[59] Monika Skaržauskaitè. THE APPLICATION OF CROWD SOURCING IN EDUCATIONAL ACTIVITIES. page 10, 2012. ISSN 2029-7564. URL https://www.mruni.eu/upload/iblock/616/005_skarzauskaite.pdf.

[60] Sophie Sun Ping and Michelangelo Magasic. Knowledge workers, identities, and communication practices: Understanding code farmers in china. 14(1), 2016-05-15. ISSN 1726-670X, 1726-670X. doi: 10.31269/triplec.v14i1.716. URL https://www.triple-c.at/index.php/tripleC/article/view/716.

[61] Melanie Swan. Crowdsourced health research studies: An important emerging complement to clinical trials in the public health research ecosystem. 14(2):e46, 2012-03-07. ISSN 1438-8871. doi: 10.2196/jmir.1988. URL http: //www.jmir.org/2012/2/e46/.

[62] A. Tarable, A. Nordio, E. Leonardi, and M. Ajmone Marsan. The importance of worker reputation information in microtask-based crowd work systems. 2016-05-26. URL http://arxiv.org/abs/1605.08261.

[63] Jaime Teevan, Shamsi T. Iqbal, and Curtis von Veh. Supporting collaborative writing with microtasks. In Proceedings of the 2016 CHI Conference on Human Factors in Computing Systems, pages 2657-2668. ACM, 2016-05-07. ISBN 978-1-4503-3362-7. doi: 10.1145/2858036.2858108. URL https://dl.acm.org/doi/10.1145/2858036.2858108.

[64] Melissa A. Valentine, Daniela Retelny, Alexandra To, Negar Rahmati, Tulsee Doshi, and Michael S. Bernstein. Flash organizations: Crowdsourcing complex work by structuring crowds as organizations. In Proceedings of the $2017 \mathrm{CHI}$ Conference on Human Factors in Computing Systems - CHI '17, pages 3523-3537. ACM Press, 2017. ISBN 978-1-45034655-9. doi: 10.1145/3025453.3025811. URL http://dl.acm.org/citation.cfm?doid=3025453.3025811.

[65] Maja Vukovic and Claudio Bartolini. Towards a research agenda for enterprise crowdsourcing. In Tiziana Margaria and Bernhard Steffen, editors, Leveraging Applications of Formal Methods, Verification, and Validation, volume 6415, pages 425-434. Springer Berlin Heidelberg, 2010. ISBN 978-3-642-16557-3 978-3-642-16558-0. doi: 10.1007/978-3-64216558-0_36. URL http://link.springer.com/10.1007/978-3-642-16558-0_36.

[66] Florian Waldner, Marion Kristin Poetz, and Marcel Bogers. Crowdsourcing business model innovation. 2016(1):10034, 2016-01. ISSN 0065-0668, 2151-6561. doi: 10.5465/ambpp.2016.10034abstract. URL http://journals.aom.org/doi/10.5465/ ambpp.2016.10034abstract.

[67] Yihong Wang, Konstantinos Papangelis, Ioanna Lykourentzou, and Vassilis-Javed Khan. The changing landscape of crowdsourcing in china: From individual crowdworkers to crowdfarms. The 22nd ACM Conference on ComputerSupported Cooperative Work and Social Computing (CSCW'19), 2019. doi: 10.1145/3311957.3359469.

[68] Yihong Wang, Konstantinos Papangelis, Michael Saker, Ioanna Lykourentzou, Alan Chamberlain, and Vassilis-Javed Khan. Crowdsourcing in china: Exploring the work experiences of solo crowdworkers and crowdfarm workers. In Proceedings of the 2020 CHI Conference on Human Factors in Computing Systems, CHI '20, page 1-13, New York, NY, USA, 2020. Association for Computing Machinery. ISBN 9781450367080. doi: 10.1145/3313831.3376473. URL 
https://doi.org/10.1145/3313831.3376473.

[69] Yihong Wang, Konstantinos Papangelis, Ioanna Lykourentzou, Hai-Ning Liang, Irwyn Sadien, Evangelia Demerouti, and Vassilis-Javed Khan. In their shoes: A structured analysis of job demands, resources, work experiences, and platform commitment of crowdworkers in china. 4:1-40, 2020-01-04. ISSN 2573-0142, 2573-0142. doi: 10.1145/3375187. URL http://dl.acm.org/doi/10.1145/3375187.

[70] Xinhua. China to explore new models to boost innovation, entrepreneurship - Business - Chinadaily.com.cn, September 2015. URL http://www.chinadaily.com.cn/business/2015-09/26/content_21989332.htm.

[71] Mohammad-Ali Yaghoub-Zadeh-Fard, Boualem Benatallah, Moshe Chai Barukh, and Shayan Zamanirad. A study of incorrect paraphrases in crowdsourced user utterances. In Proceedings of the 2019 Conference of the North, pages 295-306. Association for Computational Linguistics, 2019. doi: 10.18653/v1/N19-1026. URL http://aclweb.org/anthology/N191026.

[72] Jiang Yang, Lada A Adamic, and Mark S Ackerman. Crowdsourcing and knowledge sharing: Strategic user behavior on taskcn. page 10, 2018. 